\title{
Do Liars Believe? Beliefs and Other-Regarding Preferences in Sender-Receiver Games
}

\author{
Roman M. Sheremeta and Timothy Shields \\ Argyros School of Business and Economics, Chapman University, \\ One University Drive, Orange, CA 92866, USA.
}

December 7, 2011

\begin{abstract}
We examine subjects' behavior in sender-receiver games where there are gains from trade and alignment of interests in one of the two states. We elicit subjects' beliefs, risk and other-regarding preferences. Our design also allows us to examine the behavior of subjects in both roles, to determine whether the behavior in one role is the best response to the subject's own behavior in the other role. The results of the experiment indicate that 60 percent of senders adopt deceptive strategies by misreporting information. Nevertheless, 67 percent of receivers invest. The investing behavior of receivers cannot be explained by other-regarding or risk preferences, or as a best response to subject's own behavior in the senders' role. However, it can be rationalized by accounting for elicited beliefs. The honest behavior of some senders can be explained by other-regarding preferences. Thus we find liars do believe, and individuals who care about the payoffs of others tend to be honest.
\end{abstract}

JEL Classifications: C72, C91, D82, D83

Keywords: experiment, strategic communication, beliefs, lying, deception, other-regarding preferences,

Corresponding author: Timothy Shields, shields@chapman.edu

We would like to dedicate this paper to the memory of John Dickhaut, a mentor and a friend. For helpful comments we thank Eric Schniter, Thomas Rietz, seminar participants at Chapman University, and participants at the NorthAmerican Economic Science Association and Canadian Academic Accounting Association annual conferences. We also thank the Economic Science Institute at Chapman University for generous financial support. We retain responsibility for any errors. 


\section{Introduction}

"It is hard to believe that a man is telling the truth when you know that you would lie if you were in his place."

(H.L. Mencken)

We depend upon financial analysts to determine when to buy or sell securities, upon attorneys' assessments in deciding to pursue legal action, upon salespeople for product information, and upon doctors to undergo medical procedures. These experts hold private information that is not necessarily contractible or verifiable. Additionally, they have incentives to sway our behavior. Analysts receive commissions from transactions, attorneys from billed hours, salespeople from sales commissions, and doctors bill for procedures performed. While there are numerous examples of deception (Michaely and Womack, 1999; Franco et al., 2007), clearly people have developed behaviors such as honesty and trust to facilitate the aforementioned interactions.

A sender-receiver game (Crawford and Sobel, 1982) is a prototype of an environment that captures many real-life interactions in which an informed agent (sender) has an incentive to misreport information to an uninformed agent (receiver) due to a possible conflict of interests. This type of environment has been well studied in the lab. Blume et al. (1998), Forysthe et al. (1999), Dickhaut et al. (2003) and Cai and Wang (2006), all find that, when there is some misalignment of interests, senders convey more information than theory predicts and receivers rely upon senders' messages more than predicted. Similar behavior is documented in senderreceiver games where there is never alignment of interests. Gneezy (2005), Sanchez-Pages and Vasquez (2007) and Harken and Kartik (2009) argue that the two main reasons why senders convey more information than predicted are that subjects have other-regarding preferences for distributions and/or they are averse to lying. However, without a proper control for beliefs and 
elicitation of other-regarding preferences it is impossible to distinguish between the two alternative explanations.

We examine behavior in the sender-receiver game where there are gains to trade and alignment of subjects' interests in one of the two states. Thus, our game models the setting where there are conflicts of interest, but still some potential for cooperation. In order to tease out the determinants of behavior we measure subjects' beliefs about the behavior of others, risk and other-regarding preferences. By examining subjects' beliefs of others, not only we can identify if the sender intended to deceive others with messages sent, but can also identify whether receivers inferred information content from senders' messages. Furthermore, our design also allows us to examine the behavior of subjects in both roles, to determine whether the behavior in one role is the best response to the subject's own behavior in the other role.

The results of the experiment indicate that 60 percent of senders adopt deceptive strategies by misreporting information. Nevertheless, 67 percent of receivers invest conditional upon a favorable message. The investing behavior of receivers cannot be explained by otherregarding or risk preferences, or as a best response to the subject's own behavior in the sender's role. However, it can be rationalized by accounting for elicited beliefs about the behavior of others. Despite the appeal of Mencken's quoted prescription, we find that people believe that others are telling the truth, although these same people often tend to lie. Rather than characterizing subjects who deceive yet believe (invest) "as if they believe they are the only once capable of dishonesty" (Forysthe et al., 1999 pp. 509), we find the majority of receivers believe there are enough honest senders to warrant investment. Finally, the honest behavior of some senders can be explained by other-regarding preferences, while the other honest senders appear 
to be averse to lying. Thus we find liars do believe, and individuals who care about the payoffs of others tend to be honest.

\section{Game, Experimental Design and Procedures}

\subsection{Sender-Receiver Game}

The experimental design is based on a sender-receiver game. The game proceeds as follows. In the first stage, the sender receives a private perfect signal $\theta^{*} \in\{A, B\}$ about the true state of nature. It is public knowledge that the state of the nature is likely to be favorable with probability $\mathrm{p}(\mathrm{A})$ and unfavorable with probability $\mathrm{p}(\mathrm{B})$. In the second stage, the sender releases a public message $\theta \in\{A, B\}$ regarding the state, after receiving a private signal $\theta^{*}$. After receiving the message $\theta$, the receiver can invest his cash endowment $\eta$, in which case he receives $\pi\left(\theta^{*}\right) \in$ $\left\{\pi_{\mathrm{A}}, \pi_{\mathrm{B}}\right\}$. The investment pays $\pi_{\mathrm{B}}<\eta$ when $\theta^{*}$ is $\mathrm{B}$, and $\pi_{\mathrm{A}}>\eta$ when $\theta^{*}$ is A. If the receiver decides not to invest he retains his endowment. The sender earns compensation $\lambda>0$ if the receiver decides to invest, or else receives nothing. After the receiver makes his decision, the true state of nature $\theta^{*}$ is revealed and both players receive their payoffs based on the state and depending on the investment decision of the receiver.

Since it is always in sender's interest to persuade receiver to invest, sender has an incentive to deceive the receiver by sending message $\mathrm{A}$, when the true state of nature is $\mathrm{B}$. Anticipating deception, the receiver ignores the message sent and invests only if $\mathrm{p}(\mathrm{A}) \pi_{\mathrm{A}}+$ $\mathrm{p}(\mathrm{B}) \pi_{\mathrm{B}} \geq \eta$. Examining only pure strategies, it is trivial to prove truthful reporting cannot be sustained as an equilibrium. Alternatively, imagine the conditions needed for a mixed reporting strategy: the sender must be indifferent from reporting that the state is A or B. This dictates the receiver must have the same investing strategy for both messages received. Therefore, the 
equilibrium investment strategy is to always or never invest and the equilibrium reporting strategy is to destroy information content such that the receiver is indifferent between messages received. $^{1}$

\subsection{Experimental Parameters}

In the experiment, we set parameters such that a risk-neutral receiver should not investment. Specifically, we assume that the state of the nature is equally likely to be either favorable or unfavorable, i.e. $p(A)=p(B)=0.5$. We also set the receiver's endowment $\eta=\$ 10$, the favorable state-based payoff $\pi_{\mathrm{A}}=\$ 18$, the unfavorable state-based payoff $\pi_{\mathrm{B}}=0$, and the sender's compensation $\lambda=\$ 13$. Given these parameters, the receiver's expected payoff from investment, given that the sender's message contains no information, is $\$ 9(0.5 * \$ 18+0.5 * \$ 0)$. On the other hand, the receiver's outside payment of not investing and keeping the endowment is \$10. Therefore, standard theoretical prediction would be not to invest.

\subsection{Experimental Procedures}

The experiment was conducted at West-coast University in the United States. Subjects were recruited from a standard subject pool consisting primarily of undergraduate students. Subjects interacted with each other anonymously over a local computer network. The experiment was programmed and conducted using z-Tree (Fischbacher, 2007). The computers were placed within individual cubicles in such a way that all subjects could only view their own computer screen. The subjects acted both in the role of sender and receiver in a single one-shot interaction. We elicited the subjects' decisions using the strategy method for both roles simultaneously.

\footnotetext{
${ }^{1} \mathrm{~A}$ formal proof is available from the authors upon request.
} 
The five sessions each lasted approximately fifty-five minutes, consisted of 12 subjects each. At the beginning of each section, an experimenter read the instructions aloud while each subject followed along with their own copy of the instructions. The instructions explained the experimental procedures, payoffs, and information structures used in the experiment (instruction available in the appendix). While going over the instructions, subjects were asked to write down their answers to several questions to ensure that they understood the instructions. Subjects' answers remained confidential to other subjects. The experimenter reviewed the correct answers privately with each subject. ${ }^{2}$ During and after the instructions were read, subjects were prompted to ask the experimenter in private any questions regarding the experiment procedures.

In the first part of the experiment, each subject simultaneously played both roles of sender and receiver, by choosing what message to send for each possible private signal and whether to invest for each possible sender's message. That is, for both the favorable and unfavorable state, the sender made a binary choice to reveal the state truthfully or not. For each possible message, the receiver made a binary choice either not to invest (labeled 'Stay') or to invest (labeled 'Go'). Consequently the subject was randomly and anonymously paired with two other subjects. ${ }^{3}$ The computer randomly selected the role for payment and the state of nature, and presented an outcome screen to each individual subject. However, the outcome screen was not presented until the very end of the experiment, after all parts of the experiment were completed. ${ }^{4}$ In the second part, all subjects were asked to predict what others elected to do. Specifically, we asked subjects to provide answers to the questions listed in Table 1. The

\footnotetext{
${ }^{2}$ Subjects on average answered less than one out of 13 questions incorrectly.

${ }^{3}$ This design reflects a trade-off between the objectives of negating repeated-game/learning effects versus the possibility that subjects may be under the impression they are playing against themselves. To insure against the later, we explicitly tell subjects they are to be paired with other subjects and the decisions are independent.

${ }^{4}$ This procedure was used in order to eliminate hedging issues that may arise when eliciting behavior and beliefs. However, it is documented that hedging confounds are not a problem when hedging opportunities are not prominent (Offerman et al., 1996; Blanco et al., 2010).
} 
elicitation of beliefs was incentivized, i.e. for each correct prediction subjects received US $\$ 5$. Subjects were not aware of this task until after we elicited their choices from the first part. Subjects earned $\$ 5$ for each correct prediction; however, subjects did not learn the outcome of this task until all parts of the experiment were completed.

In the third part, we elicited subjects' risk preferences from a set of 15 lotteries as in Table 2. ${ }^{5}$ Similar to Holt and Laury (2002), in each lottery, subjects were asked to state whether they prefer a safe or risky option. Parameters were set in such a way that a subject with riskneutral preferences would select the first seven safe options. Subjects were not aware of this task until after we elicited their choices from the preceding two parts. One of the choices was randomly selected for payment at the very end of the experiment.

Finally, in the fourth part, all subjects were asked to choose paired payoffs in a task designed to elicit attitudes towards others' payoffs. $^{6}$ Specifically, we elicit responses to four binary choices that affect the subject and another. The choices of distributions, shown in Table 3, mirror those used by Bartling et al. (2009). The first option is always a pair of equal payoffs to both the subject and another paired subject. The second option is always a pair of unequal payoffs. Although option 2 always results in unequal payoffs to the subject and another, in the first two choices the subject's payoff is greater, and in the second two choices the subject's payoff is lower than that of another paired subject. ${ }^{7}$ Subjects were not aware of this task until

\footnotetext{
${ }^{5}$ Numerous experimental studies have documented risk aversion when examining subjects' behavior in a variety of tasks including lottery choices (Holt and Laury, 2002), auctions (Cox, Smith and Walker, 1988), contests (Sheremata, 2011), and coordination games (Heinemann, Nagel and Ockenfels, 2009).

${ }^{6}$ A number of experimental studies show that some subjects care about the payoffs of others (Charness and Rabin, 2002; Engelmann and Strobel, 2004).

${ }^{7}$ The choices are constructed similar to Bartling et al. (2009). Subjects choosing option 1 for the first two choices, indicate that they are ahead-averse, i.e. subjects choose not to be paid more than others. Similarly, subjects choosing option 1 for the last two choices, indicate that they are behind-averse, i.e. subjects choose not to be paid less than others consistently.
} 
after we elicited their choices from the preceding step. After subjects made their decisions, subjects were randomly paired and one of the paired subjects' choices was implemented.

Each subject was paid a $\$ 7$ participation fee, the payoffs from the scenario, their predictions, one gamble, and one distribution choice. Each participant individually signed and dated a payment receipt form and received payment. On average subjects earned \$24 in addition to their participation fee.

\section{Results}

\subsection{Description of Choices}

We found no significant differences between the five sessions and thus report the combined results. In the role of sender 40 percent of subjects ( 24 of 60 ) choose to always reveal their private information regarding the state. As shown in Figure 1, in the role of sender, all but one subject send the message A when the state is A, and 60 percent of subjects ( 36 of 60 ) send the message A when the state is B. In the role of receiver, 67 percent of subjects (40 of 60 ) choose to invest when the message is A, and only 15 percent of subjects ( 6 of 60 ) when the message is B. As shown in Figure 1, most subjects invest when the message is A, but not when the message is $\mathrm{B}$.

We classify behavior jointly and show the results in Figure 2. Subjects are classified as honest if, in the role of sender, they always reveal the true state and as deceptive if they misreport the true state. ${ }^{8}$ Similarly, in the role of receiver, subjects are classified as either choosing to invest or not (conditional upon the message). Examining the investment choices in

\footnotetext{
${ }^{8}$ Only one subject used an invertible reporting strategy, sending the message B when the state was A, and sending the message A when the state was B.
} 
Figure $2 \mathrm{a}$, when the message is $\mathrm{A}$, we find the largest proportions are honest/invest and deceptive/invest, accounting for approximately two-thirds of subjects. At the same time, examining investment choices in Figure $2 \mathrm{~b}$ we find the overwhelming majority elects to not invest when the message is $\mathrm{B}$, consistent with the inference of information content in the senders' messages. These results confirm those of Forsythe et al. (1999), who find a correlation between dishonesty and gullibility. Forsythe et al. posit that for lying to be profitable, a sender must believe that the others are dupable. Based on elicited beliefs, we examine this conjecture in the next section.

\subsection{Description of Beliefs}

Analyzing subjects' beliefs about others' behavior we find that beliefs are heterogeneous across subjects. In addition, subjects believe that others will act heterogeneously. The histograms shown in Figure 3 display the elicited beliefs (questions listed in Table 1). Most subjects believe that most senders will explicitly reveal the true state when the state is favorable (Figure 3a), while a simple majority believe most senders will send a deceptive message when the state is unfavorable (Figure 3b). As such, subjects believe that there is information content in messages. The majority of subjects also believe that receivers are likely to invest upon seeing a message suggesting a favorable state (Figure 3c), and the overwhelming majority of subjects believe that receivers are not likely to invest upon seeing an unfavorable message (Figure 3d). Consequently, subjects believe that others are dupable.

While subjects have different beliefs about the behavior of others, the average beliefs are surprisingly close to the observed behavior as shown in Table 4. On average subjects somewhat underestimate the likelihood the sender would send a favorable message when both the state is 
favorable and unfavorable. Subjects are more accurate in respect to receivers' behavior, believing that on average the majority of receivers will invest given the favorable message, but not invest given the unfavorable message.

\subsection{Description of Risk and Other-Regarding Preferences}

Next, we report the responses to the safe versus risky gamble shown in Table 2. The vast majority of subjects initially choose the safe gamble (option 1) and switch to the risky gamble (option 2) once the probability of the high payoff is larger. Figure 4 displays the number of subjects choosing $0-15$ safe options. The majority also show a tendency toward risk-averse behavior. The mean number of safe choices is 9.2 (median 9.5), while risk-neutral behavior corresponds to only 7 safe choices. A histogram of the responses in Figure 4 shows that most subjects choose one or more, but not all, risky choices. Four subjects never take a risky gamble and one always chooses the risky gamble.

Finally, we report the responses to the distributional choices shown in Table 3. The results are shown in Figure 5. We find 60 percent of subjects (36 of 60) have no measurable other-regarding preferences using our elicitation mechanism; 48 percent of subjects (29 of 60) always choose the option with the highest personal payoff; only one subject reveals utilitarian preferences. Subjects with sufficiently negative utility from receiving more than others (choosing option 2 in the first two choices of Table 3) are classified as ahead-averse, and those with sufficiently negative utility from receiving less than others (choosing option 2 in the last two choices of Table 3) are classified as behind-averse. Interestingly, 27 percent of subjects (16 of 60) are ahead-averse but not behind-averse, which is contrary to the standard assumptions about other-regarding preferences discussed in Fehr and Schmidt (1999). 


\subsection{Determinants of Behavior}

Next we look at the determinants of subjects' behavior. We conjecture that the nonequilibrium behavior of receivers can be explained by their beliefs about the behavior of others. Nearly half of subjects believe that the majority of senders will report A when the state is B, but almost all believe the majority of senders will report A when the state is A. Using the subject's elicited beliefs of senders' behavior, we construct the expected value of investing given the message was A. For the 67 percent of subjects (40 of 60) who invest when the message is A, more than half ( 21 of 40 ) have greater expected value when investing than not investing. So in addition to the 33 percent of subjects (20 of 60) who do not invest, another 35 percent ( 21 of 60 ) play a best response to their own beliefs of senders' behavior, yielding 68 percent ( 41 of 60 ) who appear acting strategically. ${ }^{9}$ Without considering risk or other-regarding preferences, we find the majority of senders' behavior is rational in light of their beliefs. This interpretation is supported by further statistical analysis.

We construct a probit regression using the subject's elicited beliefs, risk preferences and other-regarding preferences. The belief about the number of others who report A when seeing the state is A is labeled 'Beliefs sender A' while the belief about the number of others who report A when seeing the state is B is labeled 'Beliefs sender B'. We classify subjects as risk-averse if they choose eight or more safe choices. Ahead or behind aversion is also coded as binary variables. The estimation results are shown in Table 5 and Table 6 . When examining the choice to invest when the message is $\mathrm{A}$, we find that beliefs about the behavior of other senders are

\footnotetext{
${ }^{9}$ We have only 9 observations of subjects investing in the role of receiver when the message is B, with 6 of these 9 subjects telling the truth in the role of sender and 3 being deceptive and always sending message A. 8 of the 9 also invested for A. Unfortunately, the low number of observations does not allow us to make any further conclusions.
} 
significant at a 5 percent level (see Table 5). The more receivers believe that senders are honest about the true state being A the higher is the probability of investment. On the other hand, the more receivers believe that senders are dishonest about the true state being $\mathrm{B}$ the lower is the probability of investment. We also find that beliefs are somewhat important when predicting the investment decisions when the message is B (see Table 6). The reason why the results are not as strong is that there are only 15 percent of subjects ( 9 of 60 ) who invest conditional on seeing message B.

As reported in Table 5 and Table 6, neither risk nor other-regarding preferences have any significant predictive power about the behavior of receivers. In particular, when examining subjects' behavior when the sender's message is $\mathrm{A} / \mathrm{B}$, we find $66 / 15$ percent of subjects classified as risk-averse and 69/15 percent of subjects classified as risk-seeking choose to invest. ${ }^{10}$ Similarly, when the message is $\mathrm{A} / \mathrm{B}$, we find $82 / 12$ percent of subjects classified as ahead-averse and 61/16 percent not ahead-averse choose to invest. Finally, when the message is $\mathrm{A} / \mathrm{B}$, we find $75 / 13$ percent of subjects classified as behind-averse and $65 / 15$ percent not behindaverse choose to invest.

Next we look at what factors can explain the behavior of subjects in the role of a sender. From belief elicitation, we find that the majority of subjects believe that only a few will invest when seeing the message B and most will invest when seeing the message A. Such beliefs should create a bias for releasing the message A, even when the state is B. The observed behavior is consistent with these beliefs. All but one subject report message A when the state is A, and 60 percent of subjects ( 36 of 60 ) report A when the state is B. As such we cannot perform statistical

\footnotetext{
${ }^{10}$ As a robustness test, we ran the probit regressions shown in Table 5 and Table 6 with alternative measures of risk preferences. First, we used higher cutoff values of the safe choices elicited to classify risk-averse versus risk-seeking subjects. Second, instead of using a binary measure of risk aversion we used a scaled inverse tangent function. The results of these alternative estimations are very similar (both qualitatively and quantitatively) to the results reported, and are available from the authors upon request.
} 
analysis on the senders' behavior when the state is A. For those 40 percent of subjects ( 24 of 60$)$ who honestly report B, 96 percent ( 23 of 24 ) believe that receivers are more likely to invest when the message is A than when the message is B. The question is then, why do senders who see state B do not profitably deceive by sending the message A?

Two potential explanations why subjects report B is that subjects have other-regarding preferences, i.e. they care not only about own payoff but also about the payoff of others (Harken and Kartik, 2009), or that subjects are averse to lying (Gneezy, 2005; Sanchez-Pages and Vasquez, 2007). Our data allows us to separate the two explanations.

As we discussed previously, 60 percent of subjects (36 of 60) reveal no measurable otherregarding preferences, 27 percent of subjects (16 of 60) are ahead-averse, 12 percent of subjects (7 of 60) are behind-averse and 1 subject is both ahead- and behind-averse (Figure 5). Recall that 24 subjects choose to be honest by reporting B when the state is B, while they believed that it would be more profitable to lie and report A. Together with elicited beliefs and other-regarding preferences, our data indicate that almost 70 percent of the ahead-averse subjects (11 of 16) choose to be honest by reporting B when the state is B compared to only 30 percent of subjects (13 of 43) who are not ahead-averse. This suggests that 46 percent of truthful senders (11 of 24) are guided by other-regarding preferences, confirming the conjecture of Gneezy (2005) that the decision to lie depends on how much it will reduce the payoff of other subjects. However, nearly an identical number of senders (13 of 24) elected to be honest despite being neither ahead- nor behind-averse, confirming the conjecture of Harken and Kartik (2009) that some subjects are simply averse to lying. ${ }^{11}$

\footnotetext{
${ }^{11}$ Kartik et al. (2007) model the sender-receiver game where senders have preferences for truth-telling. Our work confirms that some senders opt to tell the truth despite believing others are dupable.
} 
Table 7 reports the statistical analysis consistent with these observations. A probit regression of the sender's choice when the state is B includes the subject's beliefs of others' behavior in the role of receiver, risk preferences and other-regarding preferences. Consistent with earlier observation, only ahead aversion is significant at a five percent level. Note that neither risk preferences nor beliefs have any significant predictive power about the behavior of senders when seeing the state is B. ${ }^{12}$

\section{Conclusion}

We examine subjects' behavior in scenarios where senders have valuable private information but due to conflicts of interests, might elect to deceive receivers. Like other studies we find that many senders are deceptive (60 percent), while others are honest (40 percent). Using belief elicitation procedures, we find that senders choose to be honest disregarding the fact that they have correct beliefs that lying would be more profitable. Combined with elicited otherregarding preferences, our data indicate that 46 percent of honest senders are guided by otherregarding preferences, while 54 percent are simply averse to lying without having any identifiable other-regarding preferences. Thus, our results are consistent both with Gneezy's (2005) conjecture that the decision to lie depends on how much it will reduce the payoff of other subjects and with Harken and Kartik's (2009) conjecture that some subjects are simply averse to lying.

Motivated in part by Forysthe et al. (1999), we examine the behavior of subjects in both roles, to determine whether the behavior in one role is the best response to the subject's own behavior in the other role. We find that subjects believe that others are telling the truth, although

\footnotetext{
${ }^{12}$ Examining individual data of senders when the state is $\mathrm{B}$, we do not find any consistent predictive patterns regarding beliefs and risk preferences.
} 
these same subjects often tend to lie. Moreover, most subjects act in accordance with their beliefs of others, and, on average, these beliefs are correct and mirror actual behavior. Thus, rather than characterizing subjects as dupable, or as humorously described in Forysthe et al. as "...half a sucker born every minute" (p. 509), we argue that these apparently dupable subjects play a best response to their belief that there are enough honest senders to warrant investment. 


\section{References}

Bartling, Bjorn, Ernst Fehr, Michel Andre Marechal, and Daniel Schunk. 2009. "Egalitarianism and Competitiveness.” American Economic Review, Papers \& Proceedings (99): 93-98.

Blanco, Mariana, Dirk Engelmann, Alexander Koch, and Hans-Theo Normann. 2010. "Belief elicitation in experiments: is there a hedging problem?" Experimental Economics, 3(4): 412438.

Blume, Andreas, Douglas V DeJong, Yong-Gwan Kim, and Geoffrey B Sprinkle. 1998. "Experimental Evidence on the Evolution of Meaning of Messages in Sender-Receiver Games." American Economic Review, 88(5): 1323-1340.

Cai, Hongbin, and Joseph Tao-Yi Wang. 2006. "Over communication in strategic information transmission games." Games and Economic Behavior, 56(1): 7-36.

Charness, Gary, and Matthew Rabin. 2002. "Understanding Social Preferences With Simple Tests.” Quarterly Journal of Economics, 117(3): 817-869.

Cox, James C, Vernon L Smith, and James M Walker. 1988. "Theory and individual behavior of first-price auctions." Journal of Risk and Uncertainty, 1(1): 61-99.

Crawford, Vincent, and Joel Sobel. 1982. "Strategic Information Transmission." Econometrica, 50(6): 1431-1451.

Dickhaut, John, Mergaret Ledyard, Arijit Mukherji, and Haresh Sapra. 2003. "Information management and valuation: an experimental investigation." Games and Economic Behavior, 44: $26-53$.

Engelmann, Dirk, and Martin Strobel. 2004. "Inequality Aversion, Efficiency, and Maximin Preferences in Simple Distribution Experiments." American Economic Review, 94(4): 857869.

Fehr, Ernst, and Klaus Schmidt. 1999. "A Theory of Fairness, Competition, and Cooperation.” Quarterly Journal of Economics, 114(3): 817-868.

Fischbacher, Urs. 2007. "z-Tree: Zurich toolbox for ready-made economic experiments." Experimental Economics, 10(2): 171-178.

Forsythe, Robert, Russel Lundholm, and Thomas Rietz. 1999. "Cheap talk, fraud, and adverse selection in financial markets: Some experimental evidence." Review of Financial Studies, 12(3):481-518.

Franco, Gus De, Hai Lu, and Florin P Vasvari. 2007. "Wealth Transfer Effects of Analysts' Misleading Behavior.” Journal of Accounting Research, 45(1): 71-110.

Gneezy, Uri. 2005. "Deception: The Role of Consequences." American Economic Review, 95(1), 384-394.

Heinemann, Frank, Rosemarie Nagel, and Peter Ockenfels. 2009. "Measuring Strategic Uncertainty in Coordination Games." Review of Economic Studies, 76(1): 181-221.

Holt, Charles A, and Susan K Laury. 2002. "Risk Aversion and Incentive Effects." American Economic Review, 92(5): 1644-1655.

Hurkens, Sjaak and Navin Kartik. 2009 "Would I lie to you? On social preferences and lying aversion." Experimental Economics, 12(2):180-192.

Kartik, N., Ottaviani, M., \& Squintani, F. 2007. "Credulity, lies, and costly talk." Journal of Economic Theory, 134(1), 93-116.

Michaely, Roni, and Kent L Womack. 1999. "Conflict of Interest and the Credibility of Underwriter Analyst Recommendations.” Review of Economic Studies, 12(4): 653-686. 
Offerman, Theo, Joep Sonnemans, and Arthur Schram. 1996. "Value Orientations, Expectations and Voluntary Contributions in Public Goods." Economic Journal, 106(437): 817-845.

Sanchez-Pages, S., \& Vorsatz, M. 2007. "An experimental study of truth-telling in a senderreceiver game." Games and Economic Behavior, 61(1): 86-112.

Sheremata, Roman M. 2011. "Contest Design: An Experimental Investigation." Economic Inquiry, 49(2): 573-590. 
Tables and Figures

Table 1: Elicitation of Beliefs

\begin{tabular}{ll}
\hline \hline Number & Question \\
\hline$\# 1$ & How many senders sent message $A$ when the state was $A$ ? \\
$\# 2$ & How many senders sent message $A$ when the state was $B$ ? \\
$\# 3$ & How many receivers invested when the message was $A$ ? \\
$\# 4$ & How many receivers invested when the message was $B ?$ \\
* Subjects & were asked to predict the behavior of the 12 subjects in their \\
session.
\end{tabular}

Table 2: Elicitation of Risk Preferences

\begin{tabular}{cccc}
\hline \hline & $\begin{array}{c}\text { Option } 1 \\
\text { Choice }\end{array}$ & \multicolumn{2}{c}{$\begin{array}{c}\text { Option } 2 \\
\text { Risky Option }\end{array}$} \\
\hline$\# 1$ & $\$ 1$ & $0 / 20$ of $\$ 3$ & $20 / 20$ of $\$ 0$ \\
$\# 2$ & $\$ 1$ & $1 / 20$ of $\$ 3$ & $19 / 20$ of $\$ 0$ \\
$\# 3$ & $\$ 1$ & $2 / 20$ of $\$ 3$ & $18 / 20$ of $\$ 0$ \\
$\# 4$ & $\$ 1$ & $3 / 20$ of $\$ 3$ & $17 / 20$ of $\$ 0$ \\
$\# 5$ & $\$ 1$ & $4 / 20$ of $\$ 3$ & $16 / 20$ of $\$ 0$ \\
$\# 6$ & $\$ 1$ & $5 / 20$ of $\$ 3$ & $15 / 20$ of $\$ 0$ \\
$\# 7$ & $\$ 1$ & $6 / 20$ of $\$ 3$ & $14 / 20$ of $\$ 0$ \\
$\# 8$ & $\$ 1$ & $7 / 20$ of $\$ 3$ & $13 / 20$ of $\$ 0$ \\
$\# 9$ & $\$ 1$ & $8 / 20$ of $\$ 3$ & $12 / 20$ of $\$ 0$ \\
$\# 10$ & $\$ 1$ & $9 / 20$ of $\$ 3$ & $11 / 20$ of $\$ 0$ \\
$\# 11$ & $\$ 1$ & $10 / 20$ of $\$ 3$ & $10 / 20$ of $\$ 0$ \\
$\# 12$ & $\$ 1$ & $11 / 20$ of $\$ 3$ & $9 / 20$ of $\$ 0$ \\
$\# 13$ & $\$ 1$ & $12 / 20$ of $\$ 3$ & $8 / 20$ of $\$ 0$ \\
$\# 14$ & $\$ 1$ & $13 / 20$ of $\$ 3$ & $7 / 20$ of $\$ 0$ \\
$\# 15$ & $\$ 1$ & $14 / 20$ of $\$ 3$ & $6 / 20$ of $\$ 0$ \\
\hline
\end{tabular}

* Subjects choose between a safe option 1 ( $\$ 1$ for sure) or a risky option 2 (a chance of receiving either $\$ 3$ or $\$ 0$ ).

Table 3: Elicitation of Other-Regarding Preferences

\begin{tabular}{ccc}
\hline \hline & $\begin{array}{c}\text { Option 1 } \\
\text { Self, Other }\end{array}$ & $\begin{array}{c}\text { Option } 2 \\
\text { Self, Other }\end{array}$ \\
\hline$\# 1$ & $\$ 2, \$ 2$ & $\$ 2, \$ 1$ \\
$\# 2$ & $\$ 2, \$ 2$ & $\$ 3, \$ 1$ \\
$\# 3$ & $\$ 2, \$ 2$ & $\$ 2, \$ 4$ \\
$\# 4$ & $\$ 2, \$ 2$ & $\$ 3, \$ 5$ \\
\hline
\end{tabular}

* Subjects choose between option 1 (equal payoffs) or option 2 (unequal payoffs). 
Table 4: Average Beliefs and Behavior

\begin{tabular}{lcccc}
\hline \hline & \multicolumn{2}{c}{ Reveal Signal } & \multicolumn{2}{c}{ Invest If } \\
& If Seeing State: & \multicolumn{2}{c}{ Sender's Message: } \\
\cline { 2 - 5 } & A & B & A & B \\
\hline Actual Behavior & 98.3 & 40.0 & 66.7 & 15.0 \\
Average Beliefs & 91.4 & 34.5 & 69.2 & 17.6 \\
\hline
\end{tabular}

* Percentages reported.

60 observations, probability $>$ Wald Chi2 $=0.048$, Pseudo R2 $=0.186$.

Table 5: Probability of Investment when Seeing Message A

\begin{tabular}{lrcc}
\hline \hline & Estimate & Standard Error & $P$-value \\
\hline Beliefs sender A & 0.120 & 0.043 & 0.007 \\
Beliefs sender B & -0.053 & 0.025 & 0.048 \\
Risk-averse & -0.119 & 0.125 & 0.372 \\
Ahead-averse & 0.216 & 0.123 & 0.120 \\
Behind-averse & 0.209 & 0.128 & 0.213 \\
\hline
\end{tabular}

* Robust probit regression reporting marginal effects of estimate. 60 observations, probability $>$ Wald Chi2 $=0.269$, Pseudo R2 $=0.078$.

Table 6: Probability of Investment when Seeing Message B

\begin{tabular}{lrcc}
\hline & Estimate & Standard Error & $P$-value \\
\hline Beliefs sender A & -0.014 & 0.021 & 0.599 \\
Beliefs sender B & -0.023 & 0.012 & 0.048 \\
Risk-averse & -0.003 & 0.109 & 0.980 \\
Ahead-averse & -0.102 & 0.078 & 0.211 \\
Behind-averse & -0.076 & 0.087 & 0.460 \\
\hline
\end{tabular}

* Robust probit regression reporting marginal effects of estimate.

Table 7: Probability of Sending Message B when Seeing State is B

\begin{tabular}{lrcc}
\hline \hline & Estimate & Standard Error & $P$-value \\
\hline Beliefs sender A & -0.003 & 0.021 & 0.899 \\
Beliefs sender B & 0.032 & 0.030 & 0.286 \\
Risk-averse & -0.143 & 0.169 & 0.393 \\
Ahead-averse & 0.377 & 0.146 & 0.016 \\
Behind-averse & 0.188 & 0.191 & 0.327 \\
\hline
\end{tabular}

* Robust probit regression reporting marginal effects of estimate. 60 observations, probability $>$ Wald Chi2 $=0.149$, Pseudo R2 $=0.120$. 


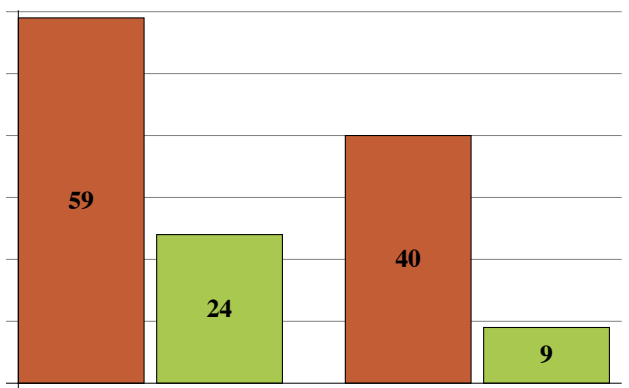

Reveal state Invest given the message $\square$ A $\square$ B

Figure 1: Number of Subjects who Reveal State or Invest given the Message

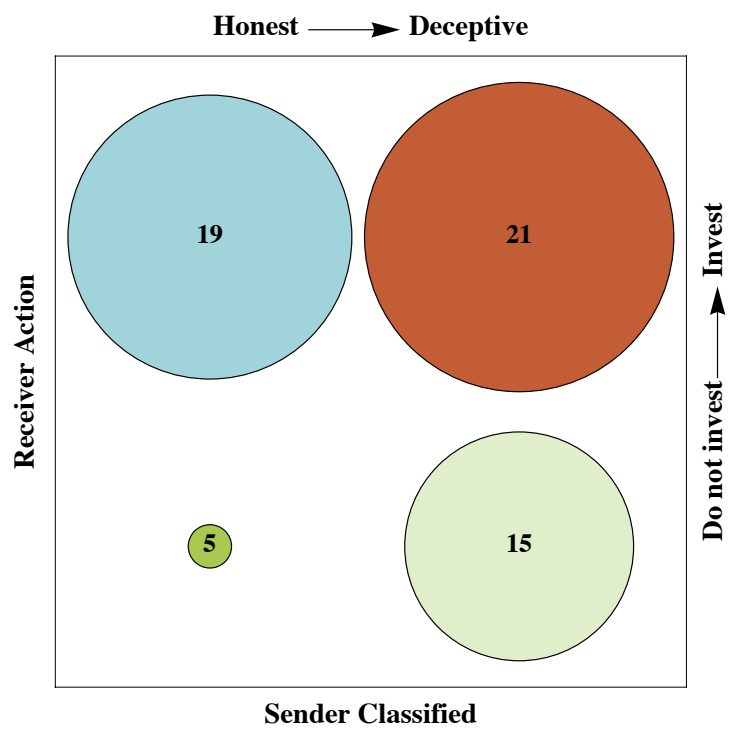

(a) Conditional on the Message A

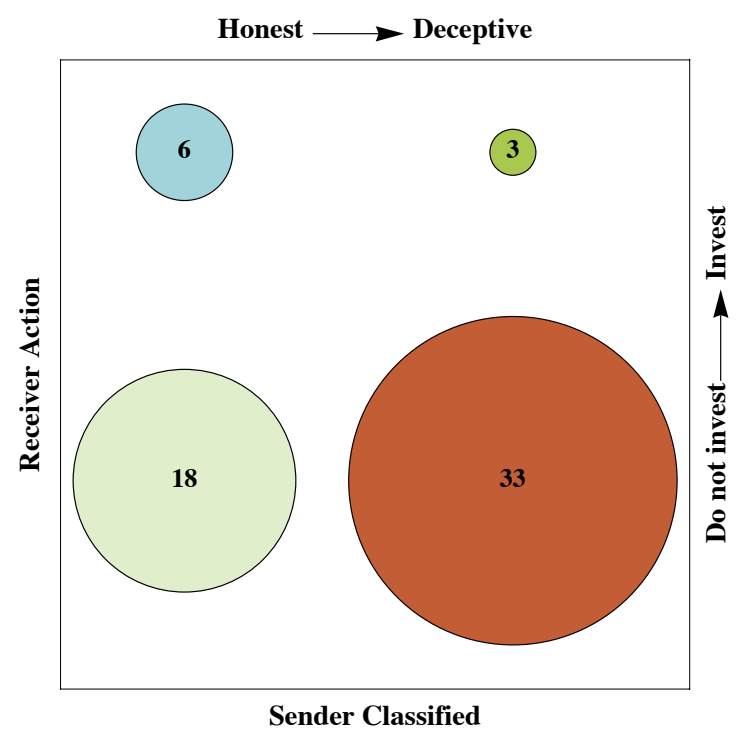

(b) Conditional on the Message B

Figure 2: Number of Subjects Grouped by Joint Choices Conditional on the Message 


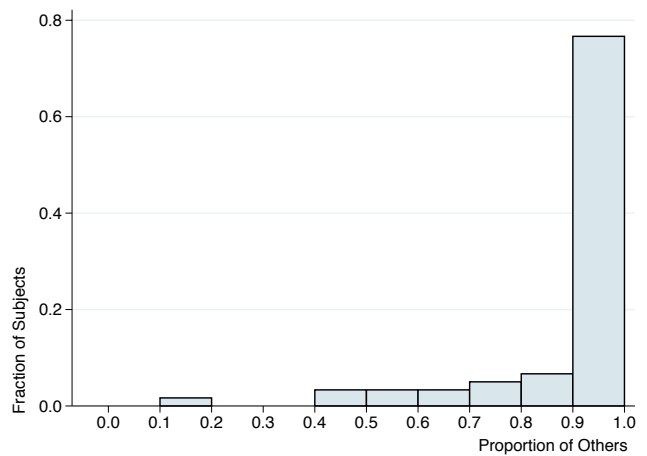

(a) Other Subjects Send Message A when Seeing State is A

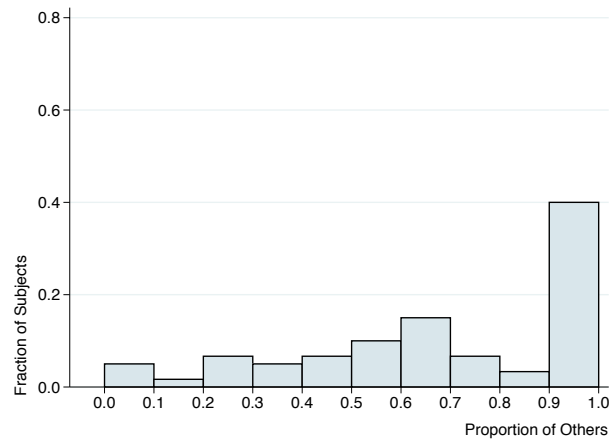

(c) Other Subjects Invest when Seeing Message A

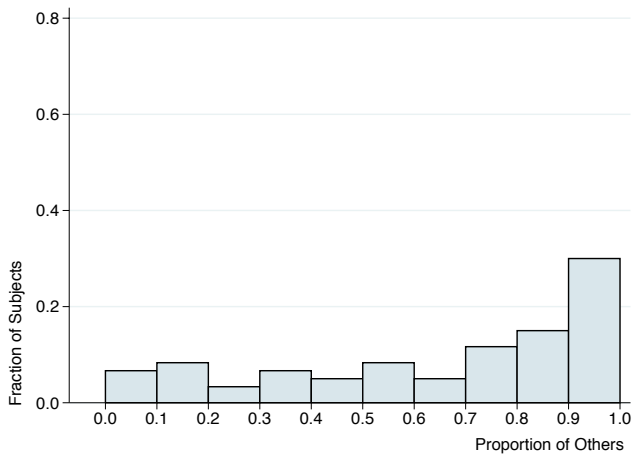

(b) Other Subjects Send Message A when Seeing State is B

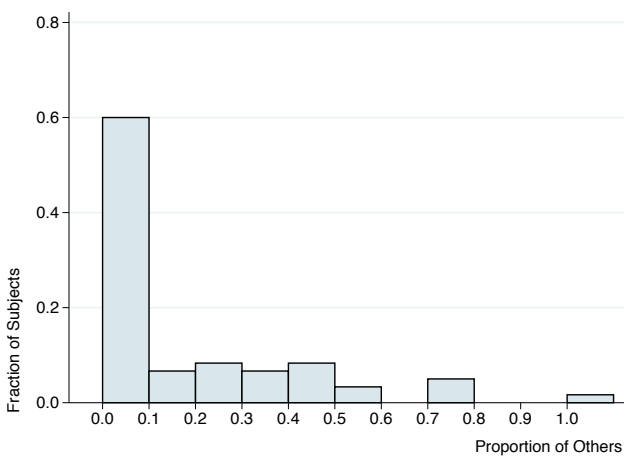

(d) Other Subjects Invest when Seeing Message B

Figure 3: Histogram of Subjects' Elicited Beliefs of Others' Behavior

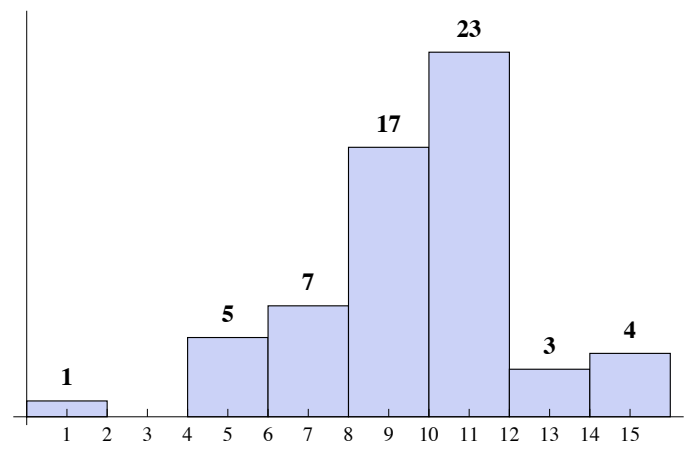

Figure 4: Number of Subjects Choosing 0-15 Safe Options 


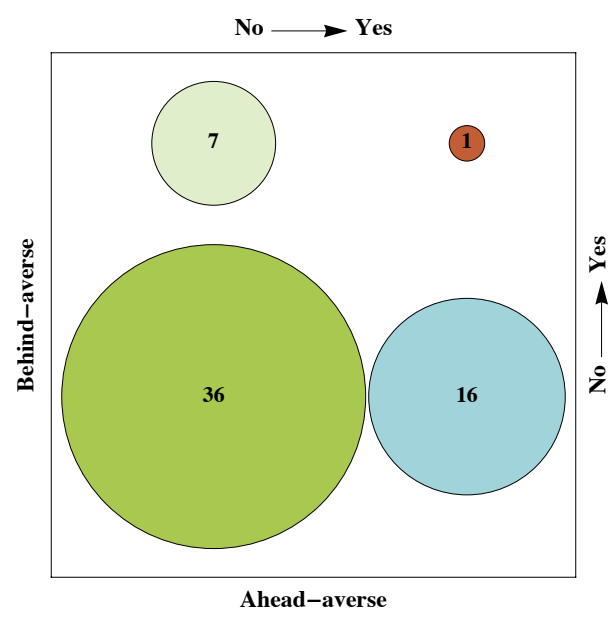

Figure 5: Number of Subjects Grouped by Attitudes towards Others' Payoffs 


\section{Not for Publication: Appendix I - Experiment Instructions}

This is a computerized experiment in the economics of decision-making. By following the instructions carefully and making good decisions, you may earn an additional amount of money besides the show up bonus of $\$ 7$. The currency used in this experiment is US dollars. The actual amount of additional money that you may earn will depend on your decisions and the decisions of other participants. Your money will be paid to you in cash after the experiment ends.

There are some rules you must follow:

1. Do not talk to others at any time during the experiment.

2. You will use your computer to select decisions during the experiment. Do not use your mouse or keyboard to play around with the software running on your computer. If you unintentionally or intentionally close the software program running on your computer, you will be asked to leave. If this happens, you will receive only your show up bonus.

3. If you have any questions during the experiment or instructions, please raise your hand. An experimenter will come to your location and answer your questions.

\section{Details of the Experiment \\ Grouping of Participants}

The experiment consists of a single round. Within this round you will be randomly paired with two other participants, but into two separate settings and thus with two separate participants. Within each setting there will be a single Sender and a single Receiver. You will make decisions as a Sender in one of the settings, and as a Receiver in the other setting. These settings are separate, as your decisions in one setting will not affect the other setting.

You will never be told whom you are paired with. You are not allowed to communicate with others during the experiment.

\section{Overview of the Setting}

All payoffs and values will be expressed in the monetary unit lira during instructions and experiment. At the end of the experiment we will convert lira to US dollars and pay you in cash.

Each Receiver has one unit of the financial asset. At the end of each round, the computer determines the State of the economy, which in turn dictates the lira value of each Receiver's asset. The chances of a particular State are:

\begin{tabular}{lll}
\multicolumn{3}{c}{ Chances of States } \\
State & $\mathrm{A}$ & $\mathrm{B}$ \\
Chance of State & $1 / 2$ & $1 / 2$
\end{tabular}

The State will be either A or B. There is an equal chance that the computer will select A or B. So, on average the computer will select A 50 percent of the time and B 50 percent of the time.

At the beginning of each round the Sender privately learns the State. No one else learns the State before the end of the round.

After the Sender learns the State, the Sender sends a Report to the Receiver. After the Receiver sees the Sender's Report, the Receiver decides to Go or Stay resulting in the following lira payoffs.

\begin{tabular}{lcc}
\multicolumn{4}{c}{ Payoffs Given State and Receiver's Decisions } \\
State is & A & B \\
\hline Receiver decides to Go & 18 & 0 \\
Receiver & 13 & 13 \\
Sender & & \\
Receiver decides to Stay & 10 & 10 \\
Receiver & 0 & 0 \\
Sender & &
\end{tabular}


Notice that only when the State is A are the payoffs higher for all parties when the Receiver decides to Go rather than to Stay. Also notice that the payoff is higher for the Sender if the Receiver decides to Go rather then to Stay in both States A and B. Last, notice that the payoffs do not depend on the Sender's Report, only on the State and whether the Receiver decides to Go or Stay.

What is the Sender's Report? If the Sender learns the State is A, the Sender can decide to report either A or B. If the Sender learns the State is B, the Sender can decide to Report A or B.

\section{Questionnaire 1}

Below, please write down your answers to the following questions. If you have a question please raise your hand and an experimenter will privately answer your question. In a few minutes, an experimenter will review the correct answers.

1. What is the chance the State will be B? $(0,1 / 2,1)$

2. If the Sender knows the State is $\mathrm{B}$, what can she report? (A,B,A or B)

3. If the Receiver knew the State was A, could he personally benefit from deciding to Go? (Yes,No)

4. If the Receiver knew the State was B, could he personally benefit from deciding to Go? (Yes,No)

5. If the Receiver decides to Go, what will the Sender receive? $(\$ 10, \$ 13)$

\section{Sender's Decision}

We will ask you to make a decision in the role of Sender in one setting. Specifically, we will ask you to make a decision about what you would report to the paired Receiver in advance of seeing the State drawn. In the role of Sender, you will see the following on your screen:

Screenshot provided to subjects at this point.

On the left side of the screen you are asked as a Sender to fill in the two entries: (i) if the State were equal to A, would you report A or B, and (ii) if the State were equal to B, would you report A or B? Specifically, for each possible State, you need to tell the computer what Report you will send.

We want you, as the Sender, to say in advance what you would do in both of the scenarios. The computer implements the decisions you make once the State is drawn. Your decision will not affect which State is drawn. Your decision in the role of Sender will not effect the outcome of the setting in which you are a Receiver.

\section{Receiver's Decision}

We will ask you to make a decision in the role of Receiver in the other setting. Specifically, we will ask you to make a decision about what you would do for each possible Report the paired Sender might send before you see the Report. In the role of Receiver, you will see the following on your screen:

\section{Screenshot provided to subjects at this point.}

On the right side of the screen you are asked as a Receiver to fill in the two entries: if (i) the Sender's Report were A, do you want to Go or Stay, and (ii) if the Sender's Report were B, do you want to Go or Stay? Although, in the end as a Receiver you would see only one Report (A or B), we still want you to tell us what you would do for each possible Report.

Your decision will not affect which Report is sent or which State drawn. Your decision in the role of Receiver will not effect the outcome of the setting in which you are a Sender.

\section{Questionnaire 2}

Below, please write down your answers to the following questions. In a few minutes, an experimenter will review the correct answers.

1. If the Sender elects to report A always, what report will the Receiver see when the State is $A$ ? $(A, B)$

2. If the Sender elects to report A always, what report will the Receiver see when the State is B? (A,B)

3. Does the Receiver always have to Go? (Yes/No)

4. If the Sender's Report is B, can the State be A? (Yes/No)

5. If the Sender's Report is A, can the State be B? (Yes/No) 


\section{Results of the Round}

After you make both your decisions, the decision in the role of Sender and the decision in the role of Receiver, click on the red 'Submit' button. After all participants input their decisions, the computer will display the outcome screen with the outcome from one of the two settings. One of your settings will be randomly selected and you will be paid on the outcome of that setting. For example, if the setting in which you played the role of Receiver was selected for payment, then your screen would show:

Results of the Round

\begin{tabular}{|l|l|}
\hline State & \\
\hline Sender's report & \\
\hline Receiver's decision & \\
\hline Sender's payoff & \\
\hline Receiver's payoff & \\
\hline
\end{tabular}

How is this table generated? After all the participants have input their decisions, the computer will draw realizations of the State independently for each pair. The computer determines the State randomly as based on Chances of State table. Given the decision input by the Sender, the Report is determined and appears under the caption 'Sender's Report'. Note this is the Sender's Report-not the State.

Next, using the decision input by the Receiver, the computer reports if the Receiver decided to Stay or Go for the given Sender's Report. This decision is reported in the row titled 'Receiver's decision'. Finally, the computer determines the payoffs (taken from Payoffs Given State and Receiver's Decisions table) given the State and the decisions for the Sender and the Receiver. These payoffs are reported in the last two rows titled 'Sender's payoff' and 'Receiver's payoff'.

To summarize, the experiment consists of a single round where:

- Grouping of Participants: pairs are randomly assigned.

- Participant's Decisions: each participant enters both a decision in the role of Sender and a decision in the role of

Receiver.

- Payoffs: the computer randomly selects one setting calculates payoffs using the decisions input.

- Results for the round: each participant sees payoff from the setting where he/she was the Sender or from the setting where he/she was the Receiver.

\section{Questionnaire 3}

Below, please write down your answers to the following questions. In a few minutes, an experimenter will review the correct answers

1. You will be paid for one of your settings, not both. (True/False)

2. If the State is A, the Sender reports 'A' when the State is A, and the Receiver decides to Go when the Report is 'A', what is:

a. The Sender's Report? (A,B)

b. The Receiver's payoff? $(0,10,18)$

c. The Sender's payoff? $(0,13)$

3. If the State is B, the Sender reports 'A' when the State is B, and Receiver decides to Stay when the Report is 'A', what is:

a. The Sender's Report? (A,B)

b. The Receiver's payoff? $(0,10,18)$

c. The Sender's payoff? $(0,13)$

The following portion was distributed after the aforementioned communication game decisions elicited.

\section{Predict What Other Participants Decided}

Before we report the results of your and other participants' decisions, we want you to tell us what you think others did. 
Every participant had to make decisions in the role of sender and in the role of receiver. We want you to predict what others did. So, we ask you to answer four questions:

1. How many participants decided to send the report ' $\mathrm{A}$ ' when the state was indeed A?

2. How many participants decided to send the report 'A' when the state was indeed B?

3. How many participants decided to Go when they saw a report of A?

4. How many participants decided to Go when they saw a report of B?

Since there are 12 participants here today, we want you to predict how many of the 12 participants answered as stated. Please enter a number no greater than 12 to each one of the questions above, including yourself (your input decision are shown). You will be paid $\$ 5$ for every correct prediction.

The following portion was distributed after the aforementioned communication game decisions and beliefs elicited.

\section{Decision Problems}

In this part of the experiment you will be asked to make a series of choices in 15 decision problems. How much you receive will depend partly on chance and partly on the choices you make. The decision problems are not designed to test you. What we want to know is what choices you would make in them. The only right answer is what you really would choose.

For each line in the table, please state whether you prefer option A or option B. Notice that there are a total of 15 lines in the table but only one line will be randomly selected for payment. Each line is equally likely to be selected, and you do not know which line will be selected when you make your choices. Hence you should pay attention to the choice you make in every line. After you have completed all your choices the computer will randomly drawn a number from 1 to 15 . The drawn number determines which line is going to be selected for payment.

Your earnings for the selected line depend on which option you chose: If you chose option A in that line, you will receive $\$ 1$. If you chose option $B$ in that line, you will receive either $\$ 3$ or $\$ 0$. To determine your earnings another number is randomly drawn from 1 to 20 . The drawn number is then compared with the numbers in the line selected (see the table). If the drawn number shows up in the left column you earn $\$ 3$. If the drawn number shows up in the right column you earn $\$ 0$.

While you have all the information in the table, we ask you that you input all your 15 choices into the computer. The actual earnings for this part will be determined at the end, and will be independent of the prior portions.

\begin{tabular}{|l||l||l|l||l|}
\hline $\begin{array}{l}\text { Deci } \\
\text { sion } \\
\text { no. }\end{array}$ & $\begin{array}{l}\text { Opti } \\
\text { on A }\end{array}$ & Option & $\begin{array}{l}\text { Please } \\
\text { B }\end{array}$ & $\begin{array}{l}\text { choose } \\
\text { A or B }\end{array}$ \\
\hline 1 & $\$ 1$ & $\$ 3$ never & $\$ 0$ if $1,2,3,4,5,6,7,8,9,10,11,12,13,14,15,16,17,18,19,20$ & \\
\hline 2 & $\$ 1$ & $\$ 3$ if 1 comes out of the bingo cage & $\$ 0$ if $2,3,4,5,6,7,8,9,10,11,12,13,14,15,16,17,18,19,20$ & \\
\hline 3 & $\$ 1$ & $\$ 3$ if 1 or 2 & $\$ 0$ if $3,4,5,6,7,8,9,10,11,12,13,14,15,16,17,18,19,20$ & \\
\hline 4 & $\$ 1$ & $\$ 3$ if $1,2,3$ & $\$ 0$ if $4,5,6,7,8,9,10,11,12,13,14,15,16,17,18,19,20$ & \\
\hline 5 & $\$ 1$ & $\$ 3$ if $1,2,3,4$, & $\$ 0$ if $5,6,7,8,9,10,11,12,13,14,15,16,17,18,19,20$ & \\
\hline 6 & $\$ 1$ & $\$ 3$ if $1,2,3,4,5$ & $\$ 0$ if $6,7,8,9,10,11,12,13,14,15,16,17,18,19,20$ & \\
\hline 7 & $\$ 1$ & $\$ 3$ if $1,2,3,4,5,6$ & $\$ 0$ if $7,8,9,10,11,12,13,14,15,16,17,18,19,20$ & \\
\hline 8 & $\$ 1$ & $\$ 3$ if $1,2,3,4,5,6,7$ & $\$ 0$ if $8,9,10,11,12,13,14,15,16,17,18,19,20$ & \\
\hline 9 & $\$ 1$ & $\$ 3$ if $1,2,3,4,5,6,7,8$ & $\$ 0$ if $9,10,11,12,13,14,15,16,17,18,19,20$ & \\
\hline 10 & $\$ 1$ & $\$ 3$ if $1,2,3,4,5,6,7,8,9$ & $\$ 0$ if $10,11,12,13,14,15,16,17,18,19,20$ & \\
\hline 11 & $\$ 1$ & $\$ 3$ if $1,2,3,4,5,6,7,8,9,10$ & $\$ 0$ if $11,12,13,14,15,16,17,18,19,20$ & \\
\hline 12 & $\$ 1$ & $\$ 3$ if $1,2,3,4,5,6,7,8,9,10,11$ & $\$ 0$ if $12,13,14,15,16,17,18,19,20$ & \\
\hline 13 & $\$ 1$ & $\$ 3$ if $1,2,3,4,5,6,7,8,9,10,11,12$ & $\$ 0$ if $13,14,15,16,17,18,19,20$ & \\
\hline 14 & $\$ 1$ & $\$ 3$ if $1,2,3,4,5,6,7,8,9,10,1,12,13$ & $\$ 0$ if $14,15,16,17,18,19,20$ & \\
\hline 15 & $\$ 1$ & $\$ 3$ if $1,2,3,4,5,6,7,8,9,10,11,12,13,14$ & $\$ 0$ if $15,16,17,18,19,20$ & \\
\hline
\end{tabular}

The following portion was distributed after the aforementioned communication game decisions, beliefs, and risk attitudes elicited. 


\section{Decision Problems}

In this part of the experiment you will be asked to make a series of choices in 4 decision problems. For each line in the table, please state whether you prefer option A or option B. Notice that there are a total of 4 lines in the table but just one line will be randomly selected for payment. Each line is equally likely to be chosen, so you should pay equal attention to the choice you make in every line. After you have completed all your choices the computer will randomly drawn a number from 1 to 4 . The drawn number determines which line is going to be selected for payment.

Your earnings for the selected line depend on which option you chose: if you chose option A in that line, you will receive $\$ 2$ and the other participant who will be matched with you will also receive $\$ 2$. If you chose option B in that line, you and the other participant will receive earnings as indicated in the table for that specific line. For example, if you chose B in line 2 and this line is selected for payment, you will receive $\$ 3$ and the other participant will receive $\$ 1$. Similarly, if you chose B in line 3 and this line is selected for payment, you will receive $\$ 2$ and the other participant will receive $\$ 4$.

After you have completed all your choices the computer will randomly determine which line is going to be paid. Then the computer will randomly and anonymously match you with another participant in the experiment. While matching you with another participant, the computer will also randomly determine whose decision to implement. If the computer chooses your decision to implement, then the earnings to you and the other participant will be determined according to your choice of A or B. If the computer chooses the other participant decision to implement, then the earnings will determined according to the other participant choice of A or B.

While you have all the information in the table, we ask you that you input all your 4 choices into the computer. The actual earnings for this part will be determined at the end, and will be independent of the prior portions.

\begin{tabular}{|l||l||l||}
\hline & $\begin{array}{l}\text { Distribution A } \\
\text { (you, the other participant) }\end{array}$ & $\begin{array}{l}\text { Distribution B } \\
\text { (you, the other participant) }\end{array}$ \\
\hline 1 & \$2 to you, \$2 to other participant & \$2 to you, \$1 to other participant \\
\hline 2 & \$2 to you, \$2 to other participant & \$3 to you, \$1 to other participant \\
\hline 3 & \$2 to you, \$2 to other participant & \$2 to you, \$4 to other participant \\
\hline 4 & \$2 to you, \$2 to other participant & \$3 to you, \$5 to other participant \\
\hline
\end{tabular}

